\title{
Access to material resources and the subjective well-being of children in Brazil and Chile
}

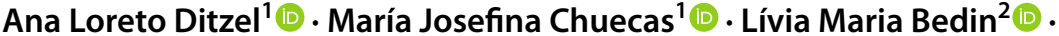

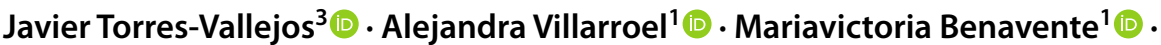 \\ Jaime Alfaro ${ }^{1}\left[\right.$. Jorge Castellá Sarriera ${ }^{4}(1)$. Joel Juarros-Basterretxea ${ }^{5}$
}

Accepted: 3 November 2021 /Published online: 17 November 2021

(c) The Author(s), under exclusive licence to Springer Nature B.V. 2021

\begin{abstract}
This article analyzes the relationships between the material conditions and the subjective well-being of 3,716 children (50.5\% girls) between 10 and 12 years of age $(M=11.4)$ in Chile and Brazil. These are the two Latin American countries that took part in the third wave of the Children's Worlds research. The material conditions of the children were assessed using latent classes. A multivariate analysis of covariance was done next in order to test the influence of material conditions over the children's subjective well-being and interpersonal relationships. The association between gender and country variables of the children was also studied. The results showed that although the average subjective well-being scores of the children were high in general, the class analysis showed significant differences between the results for children with better material conditions than those with poorer material conditions. The latter group presented lower subjective well-being levels. MANCOVA was used to analyze the mean differences in subjective well-being levels and interpersonal relationships controlling variables of gender and country of residence. This showed that children with greater access to better material conditions showed significantly higher levels of subjective well-being levels and had a more positive view of their interpersonal relationships in all areas assessed compared to those who reported worse material conditions. These results are discussed in view of the high indices of material deprivation that exist in Latin America during childhood as well as how these findings may help better understand the well-being of children living in Latin American countries.
\end{abstract}

Keywords Subjective well-being $\cdot$ Childhood $\cdot$ Material conditions $\cdot$ Interpersonal relationships · Latin America

Ana Loreto Ditzel

anaditzel@udd.cl

$\triangle$ María Josefina Chuecas

mchuecasj@udd.cl

Extended author information available on the last page of the article 


\section{Introduction}

\subsection{Subjective well-being during childhood and adolescence}

Notable importance in recent years has been assigned to studying subjective wellbeing during childhood and adolescence due to the impact it has on the mental health and positive development of this group. The study of subjective well-being has concerned itself with how people positively perceive and evaluate their own lives through both cognitive determinations and affective reactions. This is how subjective well-being couples a cognitive component, that of life satisfaction, with an affective element that is either positive or negative (Diener, 2009).

Subjective well-being measurement assesses overall life satisfaction as a whole by examining multiple aspects of an individual's life in an attempt to gain a comprehensive picture of the various domains of their lives (Seligson et al., 2003). Well-being has also been measured by evaluating satisfaction in different domains of people's lives, each of which includes a number of life areas (Diener, 2009). In terms of the domains studied, of particular note are satisfaction with oneself, one's interpersonal relationships within the family and with peers in different groups of belonging as well as the environment in which one lives (home, neighborhood, country) (Huebner \& Gilman, 2002; Weber \& Huebner, 2015).

The study of the determinants of well-being has considered the impacts of multiple factors that range from genetic factors to community conditions (Diener et al., 2018). Special attention has been given to individual, family, school and community variables along with their effects on the progression of subjective well-being during childhood and adolescence (Lee \& Yoo, 2015; Newland et al., 2019). Studies in the domain of family life have considered the perceptions held by children with respect to family life in terms of how caring, support, security and being listened to all stand out as key indicators of children's subjective wellbeing (Rees et al., 2020). The domain concerned with friendships has looked at the relationships that children have with peers their own age and the positive and negative ties that may be present (Rees et al., 2020). Children's experiences and satisfaction in the school domain have been studied, including perceptions of relationships held with both teachers and schoolmates together with attendant effects on well-being (Rees et al., 2020). The study of the domain of neighborhood experiences and how they affect children's satisfaction relates both to the sense of safety they feel in this space, the possibility of accessing places for recreation, and the chance to build positive relationships with others living in their neighborhoods (Rees et al., 2020).

A study with approximately 128,000 8- 10- and 12-year-old participants in 35 countries showed that the children indicated greater satisfaction in the life domains of family, home and their personal belongings and less satisfaction with classmates (Rees et al., 2020). Other studies in this same vein have also found that this age group has greater satisfaction in the life domain of family and less satisfaction in the domain of school life (Strózik et al., 2016). Despite such progress, however, Bradshaw and Rees (2018) indicate that children's satisfaction 
levels with various life aspects are markedly varied from country to country. Having comparative studies between countries is thus necessary.

The study of well-being during childhood and adolescence has also brought special focus to the age variable. Regardless of the fact that many children and adolescents present high levels of subjective well-being, during the transition from childhood to adolescence their levels of life satisfaction and well-being tend to go down (Bedin \& Sarriera, 2015; González-Carrasco et al., 2017). This decline usually begins around 10 years of age (Casas \& González-Carrasco, 2018). The literature suggests that such a drop is due to the changes inherent to adolescent development (in the physical, cognitive, endocrine and socio-emotional levels) as well as the pressures that are increasingly placed on this age group by the school system and their concerns about feeling they belong to and are accepted by their peer group (Žukauskienè, 2014).

Focus has also been placed on the fact that studies report disparate results with respect to subjective well-being during childhood and adolescence in terms of gender. There are studies that show no differences, while other report significant ones (Dinisman \& Ben-Arieh, 2016). One study done with 940 adolescents aged 10 to 15 years found that this difference was not detectable in terms of the overall life satisfaction of the studied group, but did find satisfaction differences by the domain (González-Carrasco et al., 2017). Likewise, one study in which more than 5,000 adolescents in 16 different countries that reported low levels of subjective wellbeing found that for girls this drop had a stronger link to interpersonal relationships, whereas for boys it was related to academic achievement (Kaye-Tzadok et al., 2017).

\subsection{The subjective well-being of children in Latin America}

The well-being of children and adolescents worldwide has also been studied, and the initiative carried out by the ISCI, the International Society of Child Indicators is of special relevance. It is called the ISCWeB: International Survey on Children Well-Being known as Children's Worlds. One of the notable achievements of the most recent version of this initiative is the comparative study of children's data from 35 countries as diverse as Namibia, Nepal and Norway (Rees et al., 2020).

Despite this substantial progress, so far very little research has included studies that compare data on the subjective well-being of children in Latin America. Work done by Newland et al. (2019) is one example of endeavors to compare the data gleaned from 14 countries in various parts of the world including Brazil and Chile. This study found that in general children had a high level of well-being and that the majority of the well-being variance could be attributed to factors related to the individual and their direct environment much more than it could to country-level factors. Another comparative study that included data on adolescents in Argentina, Brazil, Chile and Spain found that in general they had high marks for the subjective wellbeing levels with an evident decline in these levels that tracks with increasing age in all four countries (Casas et al., 2012; Sarriera et al., 2015a). Another comparative study with data from 35 countries reported that on the one hand children in Brazil 
indicated having more satisfaction with the things they had learned and less satisfaction with the sense of safety they feel. On the other hand, the children in Chile indicated having greater satisfaction in terms of what they expect for their future and less satisfaction with their neighborhoods (Rees et al., 2020).

Greater progress has been made in some Latin American countries in understanding the subjective well-being of children and adolescents at an individual level. In general, the results found in these studies agree with what is reported in international literature showing high levels of well-being in this age group (Góngora \& Castro-Solano, 2014; Guzmán et al., 2017; Sarriera et al., 2012). In Brazil a study done by Sarriera et al. (2015a) found that adolescents generally tend to report a high degree of life satisfaction. Another study in the same country with 2,135 child participants aged 9 to 13 found that their subjective well-being varied by age and family makeup. It specifically uncovered that children living with both their mother and father had higher levels of subjective well-being than those who had a different family structure (Schutz et al., 2019).

A study done in Chile with data from 1,520 students aged 8 to 14 showed that the children's well-being scores were high in general. This same study, however, also found that students in younger grade levels had greater well-being than the older grade students, that boys presented better overall well-being levels than the girls, and the students attending private schools tended to have higher wellbeing numbers than those attending other types of schools (Guzmán et al., 2017). Another study in this same country with data from 2,734 children aged 8 through 12 found that they were highly satisfied with their lives overall, with more than $70 \%$ sharing that opinion. However, upon analyzing this indicator by life domains, one sees they are highly satisfied with their health and the material things they have, but not with their interpersonal relationships with family and friends (Oyanedel et al., 2015). In contrast, another study done in Chile in which 2,938 third, fifth and seventh grade students participated showed that they were very satisfied with the life domain connected to family and less satisfied with the school domain (Alfaro et al., 2021). Despite such progress, scant literature includes individual or compiled data on Latin American children and adolescents with respect to the impacts on this group's subjective well-being created by material aspects and resources to which they have access.

\subsection{The material conditions and subjective well-being of children}

The connection between poverty and subjective well-being in childhood and adolescence has barely been investigated. Surveys like the ones from the OCDE ask people about their perceptions of financial stress and capacity to stretch the monthly budget and whether or not they consider themselves to be poor. With regards to the correlation between socioeconomic level and well-being, research with adult populations has shown a weak correlation at the individual level. This would be affected by the general social context specifically wherein the perceived levels of socioeconomic inequality affect the association between a person's income level and their well-being (Diener \& Biswas-Diener, 2002). 
In studies with children, Klocke et al. (2014) describe a close correlation between the Gini index and subjective well-being, although this has less influence than the domains of school and family do. Gadermann et al. (2015) inform us that children living in environments with high economic deprivation have a more negative wellbeing experience. This result may be related to having a hard time accessing community activities and family stress. Main (2014) reported that adolescents that come from low-income households have less satisfaction with the family and life options domains. A study conducted in northeastern Brazil with 864 children and adolescents from 9 to 18 years of age concluded that the greater the social disadvantage (measured in this study with a multidimensional poverty index), the lower the scores on the subjective well-being scales (Abreu, 2017, cited in Sarriera \& Bedin, 2017). Another study done in this same country with 543 adolescent participants and their parents indicated that the well-being means were lower for participants in the lowermiddle class as compared to the middle and upper classes (Bedin \& Sarriera, 2015). Zou et al. (2018) studied the effects of family socioeconomic status on life satisfaction for Chinese children and adolescents. They looked at optimism as a mediator of the relationship between variables and found an association between socioeconomic inequality and life satisfaction.

A growing line of research has been developing as of late concerning the association between material conditions and the well-being variables such as happiness, for example. This has raised substantial debates in the literature (Biswas-Diener, 2008). Regardless of its complexity, this relationship has been widely studied and discussed both at the individual and national levels (Gross-Manos, 2017); however, such study efforts and understanding when it comes to children and adolescents is rather limited and still in the early stages. The relevance of the study of these variables is related to the fact that the subjective measurement of material resources allows access to a subjective appreciation of the ability to satisfy basic needs, overcoming the limitations of the income measure, which does not integrate the perception of the individual regarding the enjoyment of a proper life (Boarini \& d'Ercole, 2006; SinghManoux, et al., 2003). In conjunction with the foregoing, measurements of material deprivation of this type would be a much more potent predictor of a child's sense of well-being than strictly income-based measurements (Main \& Bradshaw, 2012).

Taking this as the foundation, emerging lines of research aimed at understanding interaction between the objective perception of material resources and the wellbeing of children and adolescents (Bradshaw \& Finch, 2003; The Children's Society, 2014) as well as satisfaction with the things they have and the frequency with which they are worried about money (Gross-Manos, 2017) are in development.

Such efforts include work done by Sarriera et al. (2015b) in which they analyzed the connection between perceptions of material resource availability and subjective well-being levels in Argelia, Brazil, England, Israel, South Africa, South Korea, Spain and Uganda. Their results indicate there is a connection between the perceptions of material resource availability and well-being levels for all countries except South Korea (Sarriera et al., 2015b).

Another study with child participants living in Brazil, Chile and Spain reported that those who state having higher material conditions also had levels of happiness and life satisfaction as well as satisfaction with what might occur 
in the future at levels significantly higher than the children who reported poorer material conditions (Rees, 2021). The same study also showed that at the age of 12 years these differences in accordance with reported material conditions seemed to increase when compared to the group of 10-year-olds. Therefore, substantial differences in children's subjective well-being who report good and bad material conditions are observed. This applies both to general well-being and satisfaction with life domains.

These findings emphasize the fact that material conditions are important for children in different cultural and economic contexts. They may even feel socially excluded when they lack the material resources their peers have access to (Rees, 2021). This means that economic inequality would be an additional key variable for children and adolescents, especially when it is quite apparent in their everyday experience.

When considering a broader meaning of the material situation, which includes aspects related to the environment close to the children, such as the neighborhood, the quality of the provision of services they receive and the school environment, the association with the subjective well-being of the children increases. In a study that compared the subjective well-being of children from 14 countries, with a sample of more than 16,000 children, it was shown that low levels of material conditions and greater social exclusion were associated with lower subjective well-being scores (Gross-Manos, 2017). Lee and Yoo (2015) in an international study found that the increase in places to play safely in the neighborhood was associated with higher subjective well-being scores of children. Empirical results have also suggested that family relationships and friends may mediate or moderate the connection between poverty and children's subjective well-being. Good family relationships can prevent more extensive drops in subjective well-being (Cho, 2018).

Linked to these results, another interesting line of research that associates the material situation and poverty of children with their subjective well-being is the study of the use of time. While overall patterns of time use by children vary considerably, depending on multiple factors, Children's Worlds cross-country studies have shown some interesting associations. Evidence supports a clear association between countries with greater poverty and the frequency of children's time dedicated to work related to the home (housework and caring for other family members). On the other hand, leisure activities such as sports, watching television, and using computers are more common in high-income countries (Rees, 2017). A central concern of many countries has been the educational development of children and how situations of poverty impact the development of activities that hinder the time spent at school. An extensive comparative study between less and more industrialized countries showed that in less industrialized countries, children spend more time on household chores and work-related activities (paid and unpaid). As countries develop economically, there is greater concern that children attend school and not work. They have also found that leisure opportunities for children increase (Larson \& Verma, 1999). Thus, the evidence shows a constant pattern of greater well-being for children who live in better material conditions (Rees, 2021), understood from a perspective that includes their daily experience. 
Bearing in mind the above-described background, this article intends to use the data collected during the third wave of Children's Worlds ${ }^{1}$ research to analyze the associations between the material conditions and the subjective well-being of children in Chile and Brazil, which are the only two Latin American countries that participated in said study. More specifically, one objective is to understand the relationship between the material conditions and the different domains of interpersonal relationships. Understanding the relationships between material conditions and subjective well-being by gender and country of the children is also important. Lastly, a discussion is presented on how these findings can improve understanding of the well-being of children living in Latin American countries (Chile, Brazil).

\section{Method}

\subsection{Participants}

The total sample of participants in this study comes to 3,716 children (50.5\% girls) between 10 and 12 years of age $(M=11.4$ years); 1,787 children living in Brazil (48.1\%) and 1,929 (51.6\%) in Chile.

A total of 26 schools in Chile participated, all located in urban areas of the Metropolitan and Bio Bio Regions. The sampling strategy was representative and random for the country and was stratified based on the two most populous regions of the country (the Metropolitan and Bio Bio Regions). The sampling strategy was randomized and representative for the country, using as a sampling frame all active schools in the aforementioned regions that offered primary education.

In Brazil, we examined a sample of 1,787 adolescents $(M=11.33$ years old, $55.2 \%$ girls) from 50 public and private schools in five Brazilian states: Rio Grande do Sul, Santa Catariana, Paraná, Rio de Janeiro and São Paulo. The schools were randomly selected from a list made available by the Department of Education in each state and a class was randomly selected in each school.

\subsection{Instruments}

The study included some of the instruments used in the Children's Worlds international study (Bruck \& Ben-Arieh, 2020).

Children's Worlds Subjective Well-Being Scale (CW-SWBS). The survey items measure the cognitive dimension of subjective well-being without any context. It was designed based on the Students' Life Satisfaction Scale-SLSS (Huebner, 1991), validated in Chile and Brazil by Casas et al. (2015). This is a new version that was improved to make it more interculturally comparable in the spirit of the third wave of the Children's Worlds international study (Bruck \& Ben-Arieh, 2020).

\footnotetext{
1 Project website: www.isciweb.org
} 
The response scale format is an 11-point Likert type scale with values ranging from $0=$ "Completely disagree" up to $10=$ "Completely agree". It includes the items: "I enjoy my life", "My life is going well", "I have a good life", "The things that happen in my life are excellent", "I like my life", "I am happy with my life" $\left(\chi^{2}=56.30\right.$, $\mathrm{df}=8, \mathrm{p}<0.001 ; \mathrm{CFI}=0.998 ; \mathrm{RMSEA}=0.040$ [0.031-0.051]; SRMR =0.008). The overall index for each scale is shown as a range of $0-100$ to facilitate visual comparison.

Measuring material conditions in Children's Worlds includes eight questions with a two-choice response scale of either present (1) or absent (0). They are: 1 . clothing in good condition, 2. enough money for school trips and activities, 3. internet access at home, 4. equipment or articles needed for playing sports or pursuing hobbies, 5. pocket money/money to spend on myself, 6. two pairs of shoes in good condition, 7. a mobile phone and 8. the materials and items needed for school.

Interpersonal relationships include the relational domains of family, friends, school and neighborhood. Each of these relationships are explored using a Likert-type scale in which 0 means "I do not agree" and 4 means "I totally agree". Higher scores indicate a more positive perception of interpersonal relationships. The family relationships include 6 items, "There are people in my family who are concerned about me", "If I have a problem, people in my family will help me", "We have a good time together in my family", "I feel safe in my home", "My parents listen to me and take what I say into account", "My parents and I make decisions about my life together" $\left(\chi^{2}=26.84, \mathrm{df}=8, \mathrm{p}<0.01 ; \mathrm{CFI}=0.997\right.$; RMSEA $=0.025$ [0.015-0.036]; $\mathrm{SRMR}=0.011)$. Friendships includes 4 items, "I have enough friends", "My friends are usually nice to me", "My friends and I get along well", "If I have a problem, I have a friend who will support me" $\left(\chi^{2}=3.05\right.$, $\mathrm{df}=2, \mathrm{p}>0.05$; $\mathrm{CFI}=0.999$; RMSEA $=0.012$ [0.000-0.037]; SRMR =0.010). The school relationships include 7 items, "My teachers care about me", "If I have a problem at school my teachers will help me", "If I have a problem at school other children will help me"," My classmates fight a lot", "My teachers listen to me and take what I say into account", "I have the opportunity to make important decisions for myself at school", "I feel safe at school" $\left(\chi^{2}=118.02, \mathrm{df}=13, \mathrm{p}<0.001 ; \mathrm{CFI}=0.989\right.$; RMSEA $=0.047$ [0.0390.055]; SRMR =0.020). The neighborhood relationships include 6 items, "I feel safe walking in the area where I live", "In my area there are enough places to play or to have a good time", "If I have a problem, there are people in the area where I live who will help me", "The adults in the area where I live are nice to children", "I have the chance to help make decisions about things that are important to children in the area where I live", "The adults in the area where I live listen to children and take them seriously" $\left(\chi^{2}=86.89, \mathrm{df}=7, \mathrm{p}<0.001 ; \mathrm{CFI}=0.992 ; \mathrm{RMSEA}=0.055\right.$ [0.045-0.066]; SRMR=0.015).

\subsection{Procedure}

The data used in this study were produced as part of a larger project called Children's Worlds, the International Survey of Children's Well-Being (ISCWeB) organized by the ISCI, the International Society of Child Indicators, whose purpose is 
exploring development and well-being indicators during childhood and adolescence. This study was conducted with children and adolescents aged 8 to 12 years; however, the analyses of this study were solely conducted with data from the 10- and 12-year-old groups from the Brazilian and Chilean samples.

\subsection{Data Collection and Ethical Aspects}

\subsubsection{Chile}

The educational establishments in each region were randomized in order to select the sample. The school principals were then contacted to request authorization for implementing the study. Active informed consent was sought from the educational establishments, passive informed consent from the parents or legal guardians of the students, and then agreement from the students themselves. This is in keeping with the guidelines of the Ethics Committee at the Universidad del Desarrollo. The entirety of the survey was completed during an academic hour with the respondents. It was administered to the group, but answered individually. A research team member was present every time it was applied to answer any questions the participants may have had. The data were all collected during the second semester of 2018. The database was built using a double data entry process.

\subsubsection{Brazil}

The selected schools in Brazil were contacted. Once authorization was obtained through the Institutional Agreement and the relevant objectives and procedures were clarified, the children were invited to participate in the research. Informed Consent Forms were provided for them to take home to their parents or legal guardian as well as Agreement Forms for the students who agreed to participate and signed the Institutional Agreement. Once the Consent and Agreement Forms had been filled out and returned, a day was selected with school coordinators to collectively apply the questionnaire in a room provided by the schools with an approximate duration of $45 \mathrm{~min}$. At least two trained researchers from the team were present during the survey administration in order to address any questions and help them fill in their responses. All ethical procedures created for research on human beings were followed and the research ethics committee approved the project.

\subsection{Data analysis}

A latent classes analysis was done in order to study the children's material conditions (Masyn, 2013). A multivariate analysis of covariance (MANCOVA) was done next in order to measure the effects of material conditions upon the children's subjective well-being and interpersonal relationships. In light of the specific objectives of this study, the gender and country of residence of the children were incorporated as the covariables. 
Table 1 Means and standard deviations on the subjective well-being and interpersonal relationships scores in the total sample and by country and sex

\begin{tabular}{|c|c|c|c|c|c|}
\hline & \multirow[t]{2}{*}{ Total sample } & \multicolumn{2}{|l|}{ Country } & \multicolumn{2}{|l|}{ Gender } \\
\hline & & Brazil & Chile & Girl & Boy \\
\hline & $\mathrm{M}(\mathrm{SD})$ & $\mathrm{M}(\mathrm{SD})$ & $\mathrm{M}(\mathrm{SD})$ & $\mathrm{M}(\mathrm{SD})$ & $\mathrm{M}(\mathrm{SD})$ \\
\hline CW-SWBS & $84.42(22.28)$ & $83.14(22.97)$ & $85.56(21.59)$ & $82.24(24.41)$ & $87.04(19.03)$ \\
\hline Family Rel & $3.19(.83)$ & $3.05(.84)$ & $3.32(.80)$ & $3.15(.87)$ & $3.24(.78)$ \\
\hline Friend Rel & $3.10(.95)$ & $2.94(.97)$ & $3.24(.90)$ & $3.11(.97)$ & $3.08(.92)$ \\
\hline School Rel & $2.79(.98)$ & $2.64(.99)$ & $2.94(.95)$ & $2.79(1.00)$ & $2.80(.95)$ \\
\hline Neighborhood Rel & $2.43(1.14)$ & $2.06(1.12)$ & $2.77(1.06)$ & $2.35(1.17)$ & $2.52(1.11)$ \\
\hline
\end{tabular}

The Children's Worlds questionnaire categories were used for analyzing the interpersonal relationships, namely family, friend, school and neighborhood relationships. A factor analysis was then done to assess its behavior as a construct in this sample.

The results show that each area behaves as a single, stand-alone factor. Only the school relationships area had an item that did not add anything to the common factor, namely fighting among classmates. Upon removing it, the rest of the items behaved as a single factor.

\section{Results}

\subsection{Descriptive Results}

The general study results showed that the children in the sample had an average subjective well-being level of 84.42 points on a 0 to 100 scale $(S D=22.28$ ) (see Table 1).

The children living in Chile reported an average subjective well-being level of $85.56(S D=21.59)$ and those living in Brazil $>$ of $83.14(S D=22.97)$. Both of these differences are significant (see Table 2). Furthermore, significant differences to well-being levels by gender were detected, with an average score for the boys of $(M=87.04 ; S D=19.03)$ and the girls of $(M=82.24 S D=24.41)$ (see Table 2).

With regards to the relationship domains, one can see that the children in general have a more positive perception of their family relationships $(M=3.19 ; S D=0.83)$ compared to other domains of their lives (see Table 1).

\subsection{Latent classes analysis}

Table 3 contains the model fit indices for 2- to 5-class solutions based on the material conditions of the child participants. The results show that the $p$ values of the Lo-Mendell-Rubin (LMR) test for models 2 and 3 are significant (Masyn, 2013). Considering the sample size for each class, a two-class model was chosen. 
Table 2 Mean differences in the CW-SWBS subjective well-being scores by country of residence and sex (t-test)

\begin{tabular}{|c|c|c|c|c|c|c|}
\hline & \multicolumn{3}{|l|}{ Country } & \multicolumn{3}{|l|}{ Gender } \\
\hline & Brazil & Chile & & Girl & Boy & \\
\hline & $M(S D)$ & $M(S D)$ & $t$ & $M(S D)$ & $M(S D)$ & $t$ \\
\hline CW-SWBS & $83.14(22.97)$ & $85.56(21.59)$ & $-3.20^{* * *}$ & $82.24(24.41)$ & $87.04(19.03)$ & $6.378^{* * *}$ \\
\hline I enjoy my life, & $8.20(2.80)$ & $8.84(2.08)$ & $-7.860^{* * *}$ & $8.33(2.65)$ & $8.77(2.23)$ & $5,482^{* * *}$ \\
\hline My life is going well & $8.27(2.62)$ & $8.57(2.26)$ & $-3.736^{* * *}$ & $8.22(2.64)$ & $8.66(2.17)$ & $5,468^{* * *}$ \\
\hline I have a good life, & $8.69(2.35)$ & $8.76(2.26)$ & -0.822 & $8.60(2.46)$ & $8.90(2.07)$ & $3,940^{* * * *}$ \\
\hline $\begin{array}{l}\text { The things that hap- } \\
\text { pen in my life are } \\
\text { excellent }\end{array}$ & $7.42(2.84)$ & $7.85(2.75)$ & $-4.674^{* * *}$ & $7.41(2.97)$ & $7.92(2.56)$ & $5,512^{* * *}$ \\
\hline I like my life & $8.60(2.57)$ & $8.58(2.58)$ & 0.237 & $8.33(2.81)$ & $8.89(2.22)$ & $6,614^{* * *}$ \\
\hline $\begin{array}{l}\text { I am happy with my } \\
\text { life }\end{array}$ & $8.47(2.64)$ & $8.63(2.54)$ & -1.936 & $8.33(2.81)$ & $8.82(2.25)$ & $5,784^{* * *}$ \\
\hline
\end{tabular}

Table 3 Latent classes in material conditions for the total sample $(n=3716)$

\begin{tabular}{lllllll}
\hline N classes & AIC & BIC & aBIC & & p LMR & p bootstrap \\
\hline 2 & 17,618 & 17,736 & 17,675 & 2 vs. 1 & $<.001$ & $<.001$ \\
3 & 17,486 & 17,667 & 17,575 & 3 vs. 2 & $<.001$ & $<.001$ \\
4 & 17,474 & 17,717 & 17,593 & 4 vs. 3 & .073 & $<.001$ \\
5 & 17,462 & 17,767 & 17,611 & 5 vs. 4 & .010 & $<.001$ \\
\hline
\end{tabular}

Class 1 consists of children who reported poorer material conditions and Class 2 is made up of children who reported better material conditions (see Fig. 1). The proportion of participants in each group was $23.8 \%$ for Class $1(n=843)$ and $76.2 \%$ for Class $2(n=2864)$.

\subsection{Multivariate analysis of covariance (MANCOVA)}

MANCOVA was used to analyze the average differences in well-being and interpersonal relationships while controlling the variables of gender and country of residence. The results show that children in Class 2 with access to better material conditions showed significantly greater levels of well-being and had a more positive perception of their interpersonal relationships in every area than those who pertain to Class 1 (see Table 4). Specificaly, a greater effect size is noted for family relationships $(p \leq 0.001, g=0.733)$ followed by neighborhood relationships $(p \leq 0.001$, $g=0.711)$. 


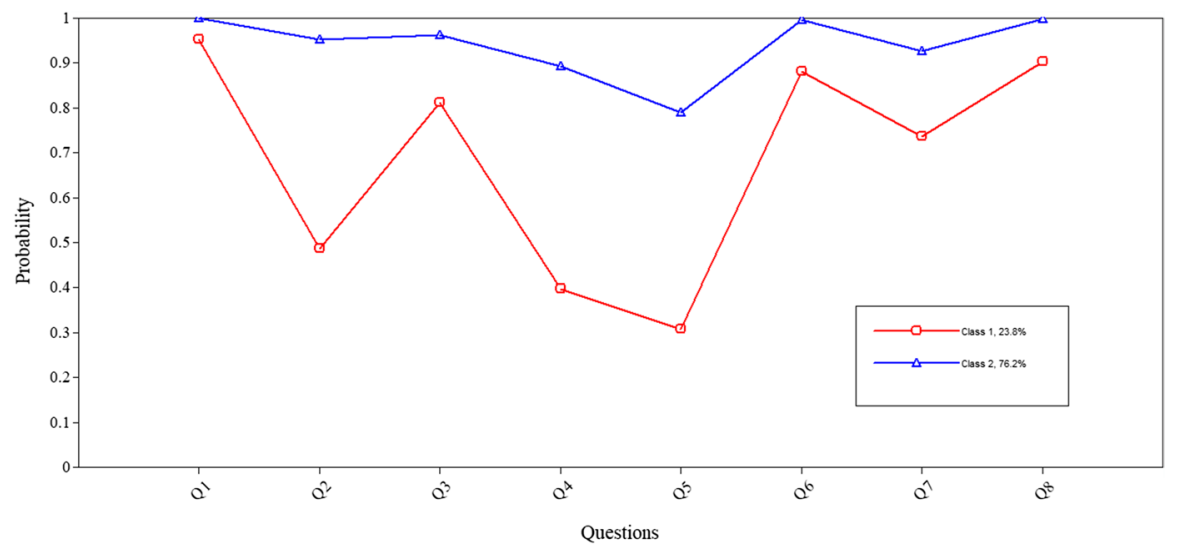

Fig. 1 Model of two latent classes

Table 4 Multivariate analysis of the subjective well-being and family relationships, controlling for the variables sex and country

\begin{tabular}{llllll}
\hline & 1 & 2 & Wilks $\lambda$ & F(sig) & Hedges' g \\
& M (SD) & M (SD) & & & \\
\hline CW-SWBS Scale & $7.36(2.74)$ & $8.73(1.91)$ & $.90^{* * *}$ & $237.805^{* * *}$ & .645 \\
Family Rel & $2.75(.95)$ & $3.33(.74)$ & & $290.833^{* * *}$ & .733 \\
Friend Rel & $2.74(1.06)$ & $3.20(.88)$ & & $131.466^{* * *}$ & .498 \\
Friend Rel & $2.40(1.02)$ & $2.92(.93)$ & & $155.303^{* * *}$ & .547 \\
Friend Rel & $1.83(1.09)$ & $2.61(1.10)$ & & $244.276^{* * *}$ & .711 \\
\hline
\end{tabular}

${ }^{* * *} p \leq .001$

\section{Discussion}

Despite the noteworthy, growing interest in a range of countries along with the public policies to foment well-being and ensure satisfactory mental health in children (Office for National Statistics [ONS], 2014), few studies have actually sought to understand how variables connected to material conditions and resource access in everyday life can impact their well-being. Even more limited yet are investigations that aim to understand this relationship by comparing countries, particularly in regions with fewer resources where one would hypothesize that the impact of material conditions is likely even greater. This is why this study sought to help fill this gap in our understanding by comparatively analyzing the subjective well-being of children in Brazil and Chile as well as examining the access they perceive they have to various material resources in everyday life.

In a general sense, the overall sample shows high levels of subjective wellbeing $(M=84.42 ; S D=22.28)$, which does concur with what has been reported in both international and local literature concerning general well-being and children's life satisfaction (Oyanedel et al., 2015; Sarriera et al., 2015a). Furthermore, 
the boys generally presented greater levels of subjective well-being than the girls. This is also consistent with what has been reported by many authors (Chen et al., 2020; Dinisman \& Ben-Arieh, 2016). For all assessed items, the boys had higher levels of subjective well-being than the girls. Such findings suggest a call to attention with respect to children's subjective well-being in these two Latin American countries. As was pointed out in the introduction, given the fact that there is no clear consensus with respect to gender differences in subjective well-being and life satisfaction levels, this research adds to the debate by providing data that shows boys having greater subjective well-being levels than girls. Likewise, given the complexity and relevance of the topic, future research would be useful for delving even more into this topic.

It is also important to note the differences observed between the two countries. In light of these results, the children living in Chile report higher subjective wellbeing levels $(M=85.56$; $S D=21.59)$ than children living in Brazil $(M=83.14$; $S D=22.97)$. Statistically significant differences were not detected for all assessed items, indicating the utility of conducting even more specific studies. Such studies would likely include additional instruments beyond subjective well-being that could broaden the understanding of these differences. To a certain degree, these results diverge from those reported by Rees (2021) that suggest that children in Brazil have happiness levels above the average for the studied countries, situated at 12 out of the 35 countries, whereas the children in Chile have a happiness mean that is slightly below average. In the Rees' study (2021), for example, it was shown that children in Brazil present both an above-average happiness score while also showing a sadness level that is above average as well. The satisfaction with life and their future are also below average for the survey. The Chilean children showed a life satisfaction level that is slightly below average, but they also present a lesser likelihood of feeling sad than the children in many of the other countries with relatively high satisfaction about their own future. On this point, it is important to bear in mind that as of today there are no studies that have solely compared these two countries. This means the results of this study signify progress in terms of understanding the subjective wellbeing of children in Latin America. This also brings about new concerns that aim to understand the contextual characteristics that could explain the differences between countries, not just between Chile and Brazil, but in Latin America overall.

Regarding the central goal of this study that aimed to understand in what way the material conditions reported by the children in Brazil and Chile connect to their subjective well-being, a directly proportional relationship among these variables was detected. This means that the children who had better material conditions and greater access to resources tend to have higher levels of subjective well-being. This finding is in line with what has been reported in the available scientific literature (Bedín \& Sarriera, 2015; Gadermann et al., 2015; Klocke et al., 2014; Rees, 2021). It is interesting to reiterate that this relationship is maintained even when controlling for the variable associated with country of residence and gender, which would offer more evidence that the impact of material conditions on well-being may be even stronger than variables related to socio-demographic conditions. Such a reflection is interesting, yet it should be viewed with caution considering the fact that more analysis is needed and other countries must be included to truly reach such conclusions. 
In particular, when analyzing the children's perception who participated in this study with respect to interpersonal relationships, significant differences came through in terms of the children's material conditions. Class 2 (better material conditions) reported having a more positive perception of their interpersonal relationships in all relationship domains (family, friend, school and neighborhood relationships) compared to Class 1 . Such results are particularly interesting given that currently, according to the evidence reviewed, there is no further data with respect to these differences and how they would impact well-being or the relationship perceptions held by the children in keeping with their material conditions. This means future studies should go into greater depth and take a more comprehensive look at this association so as to better understand how material conditions and resource access that the children have not only impact their well-being, but various relationship domains in their lives, too.

UNICEF reports (Gromada et al., 2020; UNICEF, 2007) have consistently pointed out that, based on studies from many countries worldwide, data consistently show that children growing up in poverty are more vulnerable. Among the effects observed, they are more likely to suffer from health problems, have learning and behavioral difficulties, show lower aptitudes and aspirations, and are dependent on social benefits. It must be taken into account that many children from poor families may not suffer these consequences. But this does not alter the fact that, on average, children who grow up in poverty are more likely to suffer a marked and demonstrable disadvantage. Having more time to play outside is associated with much higher levels of happiness. However, the aforementioned international reports inform that many children living in poverty indicate that there are no adequate play and recreation areas in their neighborhood.

The findings of the present study are consistent with UNICEF reports in terms of showing that material conditions are associated with children's happiness and with their interpersonal relationships in all the areas evaluated, that is, family, friends, school, the neighborhood. In other words, the group of children who reported lower material conditions presented lower levels of subjective well-being and a worse perception of their family relationships, with their friends, at school and in the neighborhood, compared to the group with better material conditions. These results show how material conditions are associated with children's well-being, from a perspective that includes their personal satisfaction, as well as their interpersonal relationships in different settings, regardless of their gender or whether they live in Chile or Brazil.

These results are particularly worrisome considering that Latin America has high indices of material scarcity, poverty and social inequality that especially impact children. This leads to risks that are not only related to lower resource access, but also to potential mental health problems. While the revised evidence shows us that the perception of poverty held by children may vary with respect to adult views and perceptions (Knies, 2011; Main, 2019), this study shows us that access to material resources by children is linked to their well-being levels. Children who report greater material deprivation present lower levels of subjective well-being.

According to economic projections, poverty indicators will currently increase as a result of the pandemic, poverty indicators will increase in the Latin American 
region (CEPAL, 2021). Although such projections are subject to constant change, available data indicate that Latin America and the Caribbean region is one of the world regions most affected by the coronavirus in terms of the number of cases and deaths. In 2020 , only $8.4 \%$ of the global population was living in the region, as of December 2020 it had $18.6 \%$ of the sum total of COVID-19 cases and $27.8 \%$ of deaths caused by this illness. Due to the COVID-19 pandemic, poverty in Latin America will reach levels that have not been seen in the last 12 years. The majority of countries will undergo a distributive deterioration. In 2020, the poverty rate was projected to reach $37.2 \%$, in circumstances that in 2019 were $30.5 \%$. While the poverty indicators in Chile and Brazil are better than the average for other countries in the region ( $10.7 \%$ and $19.2 \%$, respectively) an increase in poverty percentage are expected for 2020 by income of $14.7 \%$ in Chile and $24.1 \%$ in Brazil. Despite the efforts and emergency measures being taken by various States, such a strong economic recession will mean a worsening of life conditions as well as substantial increases in unemployment, poverty and inequality.

In the face of these serious social effects of the pandemic, children are an overrepresented vulnerable population that is living in poverty. Without considering the possible impact of social protection measures taken in the various countries, $51.3 \%$ of children and adolescents were living in poverty in 2020 (CEPAL, 2021). Despite not being the main group affected by this illness in terms of health, children, adolescents and young adults may turn out to be the primary victims of this crisis due to the consequences they will feel because of the temporary closure of educational establishments and the economic and social crises affecting their households. In a scenario such as this, taking measures aimed at children that will increase access to material resources will not only assist in their development from an economic point of view, but could also contribute to their subjective well-being.

One of the limitations of this study is that its scope was descriptive, and it has no follow-up data. Furthermore, the sample design only included urban schoolchildren. It did not collect information on ethnic minorities or other subgroups, meaning the results and conclusions must be taken with caution. Nevertheless, it is hoped that this study helps reduce the evidence gaps related to children's wellbeing concerning the evidence collected in other countries and continents.

Acknowledgements Thanks to the investigators and to all research team members who participated in the data collection of the Children's Worlds project for allowing us to use the database of Chile and Brazil and to the children who participated in the research.

Funding In Brazil, Brazilian National Council for Scientific and Technological Development (CNPq). In Chile, Faculty of Psychology, Universidad del Desarrollo.

\section{Declarations}

Conflict of interest The authors declare that they have no known competing financial interests or personal relationships that could have appeared to influence the work reported in this paper. 


\section{References}

Alfaro, J., Benavente, M., Chuecas, J., Reyes, F., Varela, J., Melipillán, R., Fábrega, J., Yaikin, T., \& Rodríguez. C. (2021). Results of the "International Survey of Children's Well-Being" (ISCWeB)- Chile Project. En Centro de Estudios en Bienestar y Convivencia Social (CEBCS), El bienestar antes, durante y después de la pandemia (pp. 12-40). Universidad del Desarrollo. https://psicologia.udd.cl/ cebcs/files/2021/01/El-bienestar-antes-durante-y-despu\%C3\%A9s-de-la-pandemia-CEBCS.pdf

Bedin, L., \& Sarriera, J. (2015). A comparative study of the subjective well-being of parents and adolescents considering gender, age, and social class. Social Indicators Research, 120, 79-95. https://doi. org/10.1007/s11205-014-0589-7

Biswas-Diener, R. (2008). Material wealth and subjective well-being. The Science of Subjective WellBeing, 307-322.

Boarini, R., \& d'Ercole, M. M. (2006). Measures of material deprivation in OECD countries. OECD Social Employment and Migration Working Papers, No. 37.

Bradshaw, J., \& Finch, N. (2003). Overlaps in dimensions of poverty. Journal of Social Policy, 32(4), 513-525.

Bradshaw, J., \& Rees, W. (2018). Children's worlds in Europe. In M. Matthes, L. Pulkkien, C. Clouder, \& B. Heys. Improving the quality of childhood in Europe. Volume 7 (pp. 163-178). Alliance for Childhood European Network Foundation, Belgium.

Bruck, S., \& Ben-Arieh, A. (2020). La historia del estudio Children's Worlds. Sociedad e Infancias, 4, 35-42. https://doi.org/10.5209/soci.68411

Casas, F., \& González-Carrasco, M. (2018). Subjective well-being decreasing with age: New research on children over 8. Child Development, 90(2), 375-394. https://doi.org/10.1111/cdev.13133

Casas, F., Sarriera, J., Abs, D., Coenders, G., Alfaro, J., Saforcada, E., \& Tonon, G. (2012). Subjective indicators of personal well-being among adolescents. Performance results for different scales in latin-language speaking countries: A contribution to the international debate. Child Indicators Research, 5, 1-28. https://doi.org/10.1007/s12187-011-9119-1

Casas, F., Alfaro, J., Sarriera, J. C., Bedin, L., Grigoras, B., Bălţătescu, S., Malo, S., \& Sirlopú, D. (2015). El bienestar subjetivo en la infancia: Estudio de la comparabilidad de 3 escalas psicométricas en 4 países de habla latina. Psicoperspectivas. Individuo y Sociedad, 14(1), 6-18. https://doi. org/10.5027/psicoperspectivas-Vol14-Issue1-fulltext-522

CEPAL (2021). Panorama social de América Latina 2020. Santiago, Chile: Naciones Unidas CEPAL. https://www.cepal.org/es/publicaciones/46687-panorama-social-america-latina-2020

Chen, X., Cai, Z., \& Fan, X. (2020). Gender differences in life satisfaction among children and adolescents: A meta-analysis. Journal of Happiness Studies, 21, 2279-2307. https://doi.org/10.1007/ s10902-019-00169-9

Cho, E.Y.-N. (2018). Links between poverty and children's subjective wellbeing: Examining the mediating and moderating role of relationships. Child Indicators Research, 11(2), 585-607. https://doi.org/ $10.1007 / \mathrm{s} 12187-017-9453-\mathrm{Z}$

Diener, E. (2009). Subjective well-being. In E. Diener (ed.), The science of well-being: The collected works of Ed Diener. Social Indicators Research Series 37. https://doi.org/10.1007/ 978-90-481-2350-62

Diener, E., \& Biswas-Diener, R. (2002). Will money increase subjective well-being? A literature review and guide to needed research. Social Indicators Research, 57, 119-169.

Diener, E., Oishi, S., \& Tay, L. (2018). Advances in subjective well-being research. Nature Human Behaviour, 2(4), 253-260. https://doi.org/10.1038/s41562-018-0307-6

Dinisman, T., \& Ben-Arieh, A. (2016). The characteristics of children's subjective well-being. Social Indicators Research, 126, 555-569. https://doi.org/10.1007/s11205-015-0921-x

Gadermann, A. M., Guhn, M., Schonert-Reichl, K., Hymel, S., Thomson, K., \& Hertzman, C. (2015). A population-based study of children's well-being and health: The relative importance of social relationships, health-related activities, and income. The Journal of Happiness Studies, 1-26. https://doi. org/10.1007/s10902-015-9673-1

Góngora, V., \& Castro-Solano, A. (2014). Well-being and life satisfaction in Argentinean adolescents. Journal of Youth Studies, 17(9), 1277-1291. https://doi.org/10.1080/13676261.2014.918251

González-Carrasco, M., Casas, F., Viñas, F., \& Dinisman, T. (2017). Changes with age in subjective wellbeing through the adolescent years: Differences by gender. Journal of Happiness Studies, 18, 63-88. https://doi.org/10.1007/s10902-016-9717-1 
Gromada, A., Rees, G., Chzhen, Y. (2020). Worlds of Influence: Understanding What Shapes Child Wellbeing in Rich Countries, Innocenti Report Card no. 16, UNICEF Office of Research - Innocenti, Florence. Retrieved from: https:/www.unicef-irc.org/publications/1140-worlds-of-influence-under standing-what-shapes-child-well-being-in-rich-countries.html. Accessed 30 Sept 2021.

Gross-Manos, D. (2017). Material well-being and social exclusion association with children's subjective Well-being: Cross-national analysis of 14 countries. Children and Youth Services Review, 80, 116128. https://doi.org/10.1016/j.childyouth.2017.06.048

Guzmán, J., Varela, J., Benavente, M., \& Sirlopú, D. (2017). Sociodemographic profile of children's wellbeing in Chile. In: Sarriera J., Bedin L. (eds) Psychosocial well-being of children and adolescents in Latin America. Children's well-being: indicators and research, vol 16. Springer. https://doi.org/10. 1007/978-3-319-55601-7_6

Huebner, E. S. (1991). Initial development of the student's life satisfaction scale. School Psychology International, 12(3), 231-240. https://doi.org/10.1177/0143034391123010.

Huebner, E. S., \& Gilman, R. (2002). An introduction to the multidimensional students' life satisfaction scale. Social Indicators Research, 60, 115-122. https://doi.org/10.1023/A:1021252812882

Kaye-Tzadok, A., Kim, S., \& Main, G. (2017). Children's subjective well-being in relation to genderWhat can we learn from dissatisfied children? Children and Youth Services Review, 80, 96-104. https://doi.org/10.1016/j.childyouth.2017.06.058

Klocke, A., Clair, A., \& Bradshaw, J. (2014). International variation in child subjective well-being. Child Indicators Research., 7(1), 1-20. https://doi.org/10.1007/s12187-013-9213-7

Knies, G. (2011). Life satisfaction and material well-being of young people in the UK. In: Understanding Society: Early Findings from the First Wave of the UK's Household Longitudinal Study. https:// www.understandingsociety.ac.uk/research/findings/early

Larson, R. W., \& Verma, S. (1999). How children and adolescents spend time across the world: Work, play, and developmental opportunities. Psychological Bulletin, 125(6), 701-736. https://doi.org/10. 1037/0033-2909.125.6.701

Lee, B., \& Yoo, M. (2015). Family, school, and community correlates of children's subjective well-being: An international comparative study. Children Indicators Research, 8, 151-175. https://doi.org/10. 1007/s12187-014-9285-z

Main, G. (2014). Child poverty and children's subjective well-being. Child Indicators Research, 7(3), 451-472. https://doi.org/10.1007/s12187-014-9237-7

Main, G. (2019). Money matters: A nuanced approach to understanding the relationship between household income and child subjective well-being. Child Indicators Research, 12(4), 1125-1145. https:// doi.org/10.1007/s12187-018-9574-z

Main, G., \& Bradshaw, J. (2012). A child material deprivation index. Child Indicators Research, 5(3), 503-521. https://doi.org/10.1007/s12187-012-9145-7.

Masyn, K. E. (2013). Latent class analysis and finite mixture modeling. In T. D. Little (Ed.), The Oxford handbook of quantitative methods: Statistical analysis (pp. 551-611). Oxford University Press.

Newland, L., Giger, J., Lawler, M., Roh, S., Brockevelt, B., \& Schweinle, A. (2019). Multilevel analysis of child and adolescents subjective well-being across 14 countries: Child- and country-level predictors. Child Development, 90(2), 395-413. https://doi.org/10.1111/cdev.13134

ONS. (2014). Measuring National Well-being - exploring the well-being of young people in the UK. Office for National Statistics.

Oyanedel, J., Alfaro, J., \& Mella, C. (2015). Bienestar subjetivo y calidad de vida en Chile. Revista Latinoamericana de Ciencias Sociales, Niñez y Juventud, 13(1). https://doi.org/10.11600/1692715x. 13118040414

Rees, G. (2017). Children's activities and time use: Variations between and within 16 countries. Children and Youth Services Review, 80, 78-87. https://doi.org/10.1016/j.childyouth.2017.06.057

Rees, G. (2021). Comparación del bienestar subjetivo de los niños en todo el mundo. Resultados de la tercera oleada del estudio Children's Worlds. Sociedad E Infancias, 5(Especial), 35-47. https://doi. org/10.5209/soci.72096

Rees, G., Savahl, S., Lee, B. J., \& Casas, F. (eds.), (2020). Children's views on their lives and well-being in 35 countries: A report on the Children's Worlds project, 2016-19. Jerusalem, Israel: Children's Worlds Project (ISCWeB). https://isciweb.org/wp-content/uploads/2020/07/Childrens-WorldsComparative-Report2020.pdf

Sarriera J. \& Bedin, L. (2017). A multidimensional approach to well-being. In Sarriera JC \& Bedin LM (Eds.), Psychosocial well- being of children and adolescents in Latin America: Evidence- based Interventions (pp. 3-26). https://doi.org/10.1007/978-3-319-55601-7_1 
Sarriera, J., Saforcada, E., Tonon, G., Rodríguez, L., Mozobancyk, S., \& Bedín, L. (2012). Bienestar subjetivo de los adolescentes: Un estudio comparativo entre Argentina y Brasil. Psychosocial Intervention, 21(3), 273-280. https://doi.org/10.5093/in2012a24

Sarriera, J., Bedin, L., Abs, D., \& Casas, F. (2015a). Relationship between social support, life satisfaction and subjective well-being in Braziian adolescents. Universitas Psychologica, 14(2), 459-474. https://doi.org/10.11144/Javeriana.upsy14-2.rbss

Sarriera, J., Casas, F., Bedin, L., Abs, D., Strelhow, M., Gross- Manos, D., \& Giger, J. (2015b). Material Resources and Children's Subjective Well-Being in Eight Countries. Child Indicators Research, 8(1), 199-209. https://doi.org/10.1007/s12187-014-9284-0

Schutz, F., Bedin, L., \& Sarriera, J. (2019). Subjective well-being of Brazilian children from different family settings. Applied Research in Quality of Life, 14, 737-750. https://doi.org/10.1007/ s11482-018-9609-0

Seligson, J. L., Huebner, E. S., \& Valois, R. F. (2003). Preliminary validation of the brief multidimensional students' life satisfaction scale (BMSLSS). Social Indicators Research, 61(2), 121-145. https://doi.org/10.1023/A:1021326822957

Singh-Manoux, A., Adler, N., \& Marmot, M. (2003). Subjective social status: Its determinants and its association with measures of ill health in the Whitehall II study. Social Science and Medicine, 56, 1321-1333.

Strózik, D., Strózik, T., \& Szwarc, K. (2016). The subjective well-being of school children The first findings from the children's worlds study in Poland. Children Indicator Research, 9(1), 39-50. https:// doi.org/10.1007/s12187-015-9312-8

The Children's Society. (2014). The Good Childhood Report 2014. The Children's Society.

UNICEF (2007). UNICEF, Child poverty in perspective: An overview of child well-being in rich countries. Innocenti Report Card 7. UNICEF Innocenti Research Centre, Florence. Retrieved from: https://www.unicef-irc.org/publications/445-child-poverty-in-perspective-an-overview-of-childwell-being-in-rich-countries.html. Accessed 30 Sept 2021.

Weber, M., \& Huebner, E. S. (2015). Early adolescents' personality and life satisfaction: A closer look at global vs. domain-specific satisfaction. Personality and Individual Differences, 83, 31-36. https:// doi.org/10.1016/j.paid.2015.03.042

Zou, R., Niu, G., Chen, W., Fan, C., Tian, Y., Sun, X., \& Zhou, Z. (2018). Socioeconomic inequality and life satisfaction in late childhood and adolescence: A moderated mediation model. Social Indicators Research, 136, 305-318. https://doi.org/10.1007/s11205-016-1542-8

Žukauskienė, R. (2014). Adolescence and Well-Being. In: Ben-Arieh A., Casas F., Frønes I., Korbin J. (eds.), Handbook of Child Well-Being (pp. 1713-1738). Springer, Dordrecht. https://doi.org/10. 1007/978-90-481-9063-8_67

Publisher's Note Springer Nature remains neutral with regard to jurisdictional claims in published maps and institutional affiliations.

\title{
Authors and Affiliations
}

\section{Ana Loreto Ditzel ${ }^{1}$ (D) María Josefina Chuecas ${ }^{1}$ (D) Lívia Maria Bedin ${ }^{2}$ (D) Javier Torres-Vallejos $^{3}$ D $\cdot$ Alejandra Villarroel $^{1}$ D $\cdot$ Mariavictoria Benavente $^{1}$ (D) . Jaime Alfaro $^{1}$ (D) Jorge Castellá Sarriera ${ }^{4}$ (D) . Joel Juarros-Basterretxea ${ }^{5}$ (D)}

\author{
Lívia Maria Bedin \\ liviabedin@gmail.com \\ Javier Torres-Vallejos \\ javier.torres@unab.cl \\ Alejandra Villarroel \\ a.villarroel@udd.cl
}

Mariavictoria Benavente mbenavented@udd.cl 
Jaime Alfaro

jalfaro@udd.cl

Jorge Castellá Sarriera

jorgesarriera@gmail.com

Joel Juarros-Basterretxea

joeljuarros@unizar.es

1 Faculty of Psychology, Universidad del Desarrollo, Av. Plaza 680, Las Condes, Santiago, Chile

2 Institute of Psychology, Universidade Federal Do Rio Grande Do Sul, Porto Alegre, Brazil

3 Faculty of Education and Social Sciences, Universidad Andres Bello, Santiago, Chile

4 Institute of Psychology, Universidade Federal Do Rio Grande Do Sul, Porto Alegre, Brazil

5 Departamento de Psicología y Sociología, Facultad de Educación, Universidad de Zaragoza, Zaragoza, España 